Oral

\title{
Perceptions Among Muslims in Malaysia Towards Dental Procedures During Fasting Month
}

\author{
Abdul Hadi Said ${ }^{1}$, Farah Natashah Mohd ${ }^{2}$ \\ ${ }^{1}$ Department of Family Medicine, Kulliyyah of Medicine, International Islamic \\ University Malaysia \\ ${ }^{2}$ Special Need Dentistry, Kulliyyah of Dentistry, International Islamic University \\ Malaysia
}

Presenter: Abdul Hadi Said

Introduction: A few studies reported that there is reduced in dental attendance among Muslim patients during fasting month. This study aims to assess the perceptions among Muslims in Malaysia on common dental procedures during fasting. Materials and Methods: A structured questionnaire was used to assess the perception about common dental procedures and dental attendance during fasting on 377 Muslim adults in Kuantan, Malaysia. The total cumulative score derived from the perception section was categorized into good and poor perception based on the median score, where a score less than the median score was categorized as poor perception and a score equal to or more than the median score was categorized as good perception. We further examined the association between perception score with sociodemographic data and dental attendance. Results: Majority respondents perceived that most of the dental procedures will not nullify their fast with $50.9 \%$ of them categorized as having a good perception based on median score. There was a significant association between perception with education level $(p=0.04)$ and Islamic education level $(p<0.001)$. There was also a significant association between their perception and dental attendance during fasting month $(p=0.04)$. It also showed that dental attendance during fasting month was poor across both groups with poor and good perception. Conclusion: The majority of the Muslims perceived that most dental procedures did not nullify their fast. However, their willingness to come for dental treatment during fasting was poor regardless of the perceptions. Hence, further research is necessary to explore the reason behind this. 